\title{
DOCUMENTOS
}

\section{La pregunta por la forma en la música sinfónica de Oscar Strasnoy}

\section{The question about form in the symphonic music of Oscar Strasnoy}

\author{
por \\ Pablo Fessel \\ Instituto de Teoría e Historia del Arte "Julio E. Payró", \\ Facultad de Filosofía y Letras, Universidad de Buenos Aires, Argentina. \\ pablo.fessel@gmail.com
}

La reintroducción de los géneros, así como la diversificación de procedimientos intertextuales en la música de concierto a partir de los años setenta del siglo XX, dio lugar a un intenso debate respecto de sus orientaciones estéticas e históricas. El artículo analiza dos obras del compositor argentino Oscar Strasnoy, Sum (2005-11), cuatro piezas para orquesta sinfónica; y Trois caprices de Paganini (2011), concierto para violín y orquesta. Se propone que el recurso a la historia se inscribe, en este caso, en una orientación modernista, como un nominalismo estético que desprende las obras de sus contextos (históricos o estilísticos), identificando elementos de modernidad en las expresiones del pasado, que entran en diálogo con el pensamiento musical contemporáneo.

Palabras clave: música contemporánea argentina, obras para orquesta, intertextualidad, forma musical, nominalismo estético.

The reintroduction of genres in late twentieth-century concert music, as well as the diversification of intertextual procedures, resulted in an intense debate regarding their aesthetic and historical orientations. The article analyzes two works by the Argentinean composer Oscar Strasnoy: Sum, four pieces for symphonic orchestra (2005-11); and Trois caprices de Paganini (2011), a concert for violin and orchestra. It is proposed that the appeal to history is inscribed in this case in a late-modernist orientation, as an aesthetic nominalism that detaches the works from their contexts (historical or stylistic), identifying elements of modernity in expressions of the past that enter into a dialogue with contemporary musical thought.

Keywords: Argentine Contemporary Music, Orchestral Music, Intertextuality, Musical Form, Aesthetic Nominalism.

I

Uno de los procesos que atraviesan la historia de la música de concierto del siglo XX, considerada en el plano de la larga duración y desde el punto de vista de la historia de la composición, es la radicalización del principio decimonónico de la originalidad, que del tema y la armonía se extendió, primero en la segunda escuela de Viena y luego en el círculo de Darmstadt, a la sintaxis entera y a la misma forma ${ }^{1}$.

1 Una versión previa de este artículo fue presentada en las X Jornadas del Instituto de Teoría e Historia del Arte y publicada en sus Actas: La teoría e historia del arte frente a los debates de la globalización

Revista Musical Chilena, Año LXXV, enero-junio, 2021, No 235, pp. 201-216 Fecha de recepción: 08-07-2019. Fecha de aceptación: 29-01-2020 
Theodor W. Adorno interpretó ese proceso, constitutivo de la modernidad estética, como un proceso de nominalismo creciente, de acuerdo con ello; los elementos particulares que impulsan la obra de arte hacia su autonomía e individuación entran en contradicción con los aspectos generales que la subsumen en un colectivo, social y estético ${ }^{2}$. En ese proceso, los elementos particulares eventualmente se imponen, dando como resultado una fractura, una disolución de los universales que alcanzó naturalmente a los mismos géneros estéticos (Cf. Dahlhaus 1987 y 2000), con un consiguiente problema de inteligibilidad. No es difícil entender a partir de este diagnóstico el rechazo adorniano del neoclasicismo en general, y de lo que él mismo denominó "música sobre música”, en particular (Cf. Adorno 2003: 159-63). Se trataba, en el análisis de Adorno, de orientaciones regresivas ${ }^{3}$.

La reintroducción de los géneros a partir de los años setenta del siglo XX podría entenderse también, en esa línea interpretativa, como una reacción conservadora ante lo que algunos compositores experimentaron como un agotamiento del concepto modernista de material musical ${ }^{4}$. Depositario de una demanda estética de renovada originalidad, sus desarrollos, incluidos los de la deriva electrónica, dieron lugar sin embargo a nuevos clichés ${ }^{5}$, a la vez que profundizaron el abismo comunicativo iniciado en las primeras décadas del siglo con la crisis de la tonalidad. Los géneros tradicionales, así como un

y la posmodernidad (Buenos Aires: Facultad de Filosofía y Letras, 2014), pp. 485-90. La reelaboración del texto se realizó en el marco del proyecto de investigación "Poéticas de la música contemporánea argentina post-CLAEM (Di Tella)", (PICT 2017-2138) radicado en el Instituto de Teoría e Historia del Arte "Julio E. Payró" de la Facultad de Filosofía y Letras (Universidad de Buenos Aires). Agradezco a los evaluadores anónimos las observaciones que me permitieron aclarar y desarrollar algunos de los temas tratados.

2 Cf. Adorno 2004: 265-72. En la interpretación de Adorno el presupuesto nominalista tradicional, de acuerdo con el que los conceptos son lógicamente posteriores a las realidades que designan, asume en el desarrollo histórico del arte de la modernidad una forma en que los elementos ligados a lo particular (los materiales) se colocan en contradicción con las categorías generales, dadas previamente por la tradición, a las cuales rechazan en tanto "formas dadas [de antemano]" (Adorno 2004: 291). Se establece así una primacía de lo particular por sobre lo general, lo que conlleva una crítica inmanente de esto último. Esta orientación nominalista ha sido reconocida por el propio Adorno como uno de los elementos que caracterizan la estética de la Nueva Música. Rudolph Stephan (1969) distinguió lo nuevo de la Nueva Música en el hecho de que en esta no se realiza simplemente la pérdida de elementos normativos de un lenguaje musical particular y su sustitución por otros, sino, idealmente, una pérdida del carácter vinculante en sí de toda norma exterior a la obra misma. Es la generalidad misma del lenguaje musical, escribe Stephan, lo que se disuelve.

3 Paradójicamente, la crítica de Adorno de Stravinsky en particular se sostiene en premisas organicistas, que la Nueva Música no tardaría en revisar.

4 Cf. Monjeau 2009: 140. Este transformó básicamente la dialéctica iluminista de apego a la convención y a la vez desvío de esta en una de constante evolución hacia lo inaudito. Adorno subrayó el carácter histórico de los materiales musicales, aun cuando toman la forma de una completa deshistorización. Cf. Adorno 2004: 200-201.

5 Estos clichés resultaron de la generalización de lo que podría denominarse una "retórica weberniana": una profusión de grandes intervalos, con líneas melódicas caracterizables por la disyunción interválica y los enlaces cromáticos. Gerardo Gandini interpretó en varias ocasiones la apelación a la historia en sus obras como una reacción frente a los estereotipos en los que había incurrido la música de vanguardia en los años cincuenta y sesenta: "Este mecanismo de elaboración de los materiales fue, en mi caso particular, consecuencia de una necesidad de recurrir a la música del pasado, como una opción o reacción contra las tendencias que por entonces se habían impuesto como moda. En los años 70 se generalizó la vanguardia en modelos estereotipados, recurriendo la mayoría de los compositores a los mismos clisés y dando como resultado obras que sonaban casi idénticas, puesto que casi todos combinaban los mismos 'gestos"” (Gandini 1995: 15-16). 
reanimado interés por los procedimientos intertextuales ${ }^{6}$, habrían encontrado de este modo en el pasado una suerte de salvavidas estético para resolver esos dilemas ${ }^{7}$.

Creo que es posible, sin embargo, considerar una interpretación alternativa, no necesariamente contradictoria con el diagnóstico adorniano. Mientras que la apelación a la historia puede entenderse en compositores como George Rochberg o Alfred Schnittke como expresión de una cierta nostalgia (Cf. Hicks 1984, citado en Metzer 2003: 118), o como apelación a una presunta inmediatez emocional (Cf. De la Motte-Haber 1990: 390) -ambas expresión de una sensibilidad postmoderna-, esa apelación representa en cambio, en compositores como Mauricio Kagel, Dieter Schnebel o Gerardo Gandini, la continuidad y desarrollo del mismo impulso modernista ${ }^{8}$. Puede interpretarse, de hecho, como un nominalismo que desprende las obras de sus contextos (históricos, estilísticos), identificando elementos de modernidad en las expresiones del pasado que entran en diálogo con el pensamiento musical contemporáneo ${ }^{9}$. Así, Dieter Schnebel, por ejemplo, refiriéndose a su ciclo Re-Visionen, escribió:

$\mathrm{Al}$ ciclo Re-Visionen [Re-Visiones] lo denominé originalmente Bearbeitungen [Arreglos], y eso significaba no solo varear la calcificación de las convenciones, sino también explotar y al mismo tiempo tallar el potencial del pasado, sus posibilidades acaso todavía no descubiertas [...], o más sutilmente: extraerlas, filtrarlas; o en términos poético-filosóficos: contemplarlas -a lo que alude

6 Empleo ex profeso el término "intertextualidad" en sentido amplio (por contraste con el sentido restringido que tiene por ejemplo en Genette 1989) como referencia al vasto conjunto de procedimientos de remisión, alusión, cita, préstamo, entre otros, para remitirlos de modo general a la tradición intelectual que inicia Julia Kristeva en Kristeva 1967. Cf. la consideración del concepto por parte de Tobias Bleek, quien lo contrapone a otros como los de "préstamo", "música sobre música", y "autorreflexión musical” en Bleek 2010: 18-43. Como señala J. Peter Burkholder (1995: 4-5), las líneas que distinguen los diferentes procedimientos en que esta se manifiesta (cita, parodia, alusión, paráfrasis, entre otros) no son fijas y suelen desdibujarse en la práctica. Lo mismo se aplica a las distinciones relativas a los sentidos que aquellos pueden asumir en cada caso.

7 Estos dos fenómenos, la reintroducción de los géneros y la intertextualidad, frecuentemente combinados, fueron caracterizados, no sin polémica (cf. Williams 1997: 119-48), como las expresiones más conspicuas de posmodernismo en la música contemporánea de esos años (cf. Metzer 2003). El debate en torno a modernismo y posmodernismo en la música del siglo XX exhibe desacuerdos importantes que hacen a su caracterización en términos estéticos y políticos (su carácter afirmativo o crítico; cf. Williams 2001: 115); su estatuto como designación de una sensibilidad de época (De la Motte-Haber 1990: 386; Tillman, 2002: 86); su relación recíproca (Williams 1997; Heile 2002; Metzer 2009); y su representación en términos de los compositores, obras, o procedimientos que pueden adscribirse a uno u otro (Danuser 2014; Kramer 1997; Williams 2013). Las vicisitudes de ese debate en los ámbitos germanoparlante y angloparlante, incluida su misma pertinencia respecto del campo musical, están bien reflejadas en Kolleritsch 1993 y Lochhead y Auner 2002. La discusión se volvió en cierto sentido insalvable, al punto que Danuser (1988: 4) se refirió a la iridiscencia del término posmodernismo, crecientemente oscurecido a medida que la polémica fue extendiéndose en el tiempo. Lo decisivo del debate depende de si la relación entre sus términos se plantea como antagónica (el posmodernismo como antimodernismo) o como de reinterpretación (el posmodernismo como revisión crítica y continuación del modernismo) Cf. Danuser 2014. Si se entiende el posmodernismo como "una sensibilidad contemporánea dominante que aboga por lo particular sobre lo general" (Williams 2001: 115. Postmodernism is a dominant contemporary sensibility that champions the particular over the general), la relevancia de la distinción misma puede ponerse en cuestión.

8 El impulso modernista estaría dado por una orientación a la "progresiva negación de sentido" (Adorno, cit. en Wellmer 1993: 63): una crítica inmanente a la autoridad y naturalidad de lo dado (social y estético). En este caso en particular, se trataría de una crítica a la idea de tradición como "puro pasado".

9 Para una lectura igualmente modernista de las operaciones intertextuales en obras de Luciano Berio, Karlheinz Stockhausen o Bernd Alois Zimmermann, cf. Danuser 1988: 9; Metzer 2003: 116 y 136; y Williams 2013: 49-52. Este último interpreta también la música de Wolfgang Rihm en esa clave (2013: 183-84). 
el nuevo título Re-Visionen. Se trataría también de abrirse paso a estratos que recién ahora pueden experimentarse auténticamente, o que incluso parecen contemporáneos ${ }^{10}$.

El modernismo rechaza la tradición en lo que esta tiene de práctica irreflexiva, sostenida en una repetición cuasirritual, olvidada de su necesidad original. La intervención selectiva de estos compositores acerca de la tradición no restaura el momento acrítico, sino que extiende esa crítica a la música del pasado (Cf. Adorno 2008).

La música de Oscar Strasnoy (n. Buenos Aires, 1970) también puede ser interpretada en esa clave. El presente artículo analiza el primer segmento de su producción sinfónica: las cuatro piezas que componen el ciclo Sum (2005-12) y el concierto para violín Trois caprices de Paganini (2011), con el fin de caracterizar las modalidades de apropiación de materiales no originales, así como su sentido en la composición de la obra en cada caso ${ }^{11}$. Las conclusiones proponen una interpretación relacionada con la inserción de la poética musical de Strasnoy en el campo de la música contemporánea argentina.

II

El título de Sum, cuatro piezas para orquesta sinfónica, articula una doble alusión: al prefijo del griego antiguo ouv (juntos, en conjunto), raíz del término que designa el género sinfónico, y al término latino summa, con su idea de agregado y de sustancia propia, de culminación. Origen y devenir: Strasnoy revisa los fundamentos del género a partir de una relectura de algunas de sus realizaciones emblemáticas en la tradición occidental ${ }^{12}$.

Todo primer movimiento en la era del nominalismo responde implícitamente una pregunta acerca de cómo comenzar. Incipit (8'46"), la primera pieza de Sum, ${ }^{13}$ agrega a la respuesta particular que ofrece, la formulación de la misma pregunta, bajo la forma de una revisión irónica de un conjunto de comienzos, citados y transfigurados. Strasnoy hace de ese momento inaugural de la escucha, en el que de acuerdo con el organicismo estético se cifran las premisas que la irán a guiar durante el desenvolvimiento de la forma, su materia misma.

Incipit comienza con una cita del comienzo de la Quinta Sinfonía de Gustav Mahler a la que se agrega el de Le Sacre du Printemps, de Igor Stravinsky, reducido inicialmente a solo su primera nota. Esta se prolonga (más tiempo de lo que lo hace en Le Sacre) y vuelve a escucharse el motivo de la trompeta de la quinta de Mahler, aunque ya no como anacrusa sino en el tiempo fuerte de c. 4, como desinencia. En ambos casos -y más adelante, en casi todos-, Strasnoy mantiene la altura, el registro y la orquestación original de los materiales citados (ver Ejemplo 1).

10 Schnebel 1998: 2. Der Zyklus Re-Visionen I hieß ursprünglich Bearbeitungen, und das meint nicht nur, die Verkalkungen des Konventionellen abzuschlagen, sondern auch das Potential des Vergangenen, seine vielleicht noch unentdeckten Möglichkeiten zu erschließen, gleichsam herauszuhauen (...) oder zarter: herauszuziehen, herauszufiltern; oder poetisch philosophisch: zu erschauen - wie es der neuere Titel Re-Visionen meint. Also wäre zu den Schichten durchzudringen, die heute erst recht erlebbar werden oder gar gegenwärtig erscheinen.

11 No considero obras más recientes como Automaton (2016), para violín y orquesta; Kuleshov (2017), para piano y orquesta; o Ittingen-Concerto (2017) para orquesta de cámara; cuyo análisis demanda un artículo específico.

12 Las cuatro piezas fueron compuestas en forma independiente, con algunos años de distancia entre sí, y son frecuentemente interpretadas en forma individual. Dispuestas en el orden que les provee su numeración en el ciclo es más clara la remisión a las convenciones de la sinfonía como género. No obstante, esa disposición no es obligada, ni está reflejada en el primer registro comercial de la obra (véase Strasnoy 2013). Las referencias del ciclo al género sinfónico, tanto como la remisión etimológica de su título, lo ubican en línea con los casos de metamúsica que analiza Hermann Danuser en su apartado acerca de metarreferencias. Cf. Danuser 2017: 54-65.

13 Sum no. 1 (2009-11), dedicada a Peter Eötvös. Obra encargada por la Radio France, y compuesta con apoyo de la Fundación J. S. Guggenheim. Las duraciones están tomadas de las versiones editadas en Strasnoy 2013. La obra se encuentra actualmente en revisión. Las referencias que siguen se basan en la versión interpretada el 14 de enero de 2012 en París por la Orquesta Filarmónica de Radio France en el marco del Festival Présences 2012 dedicado a Strasnoy. 


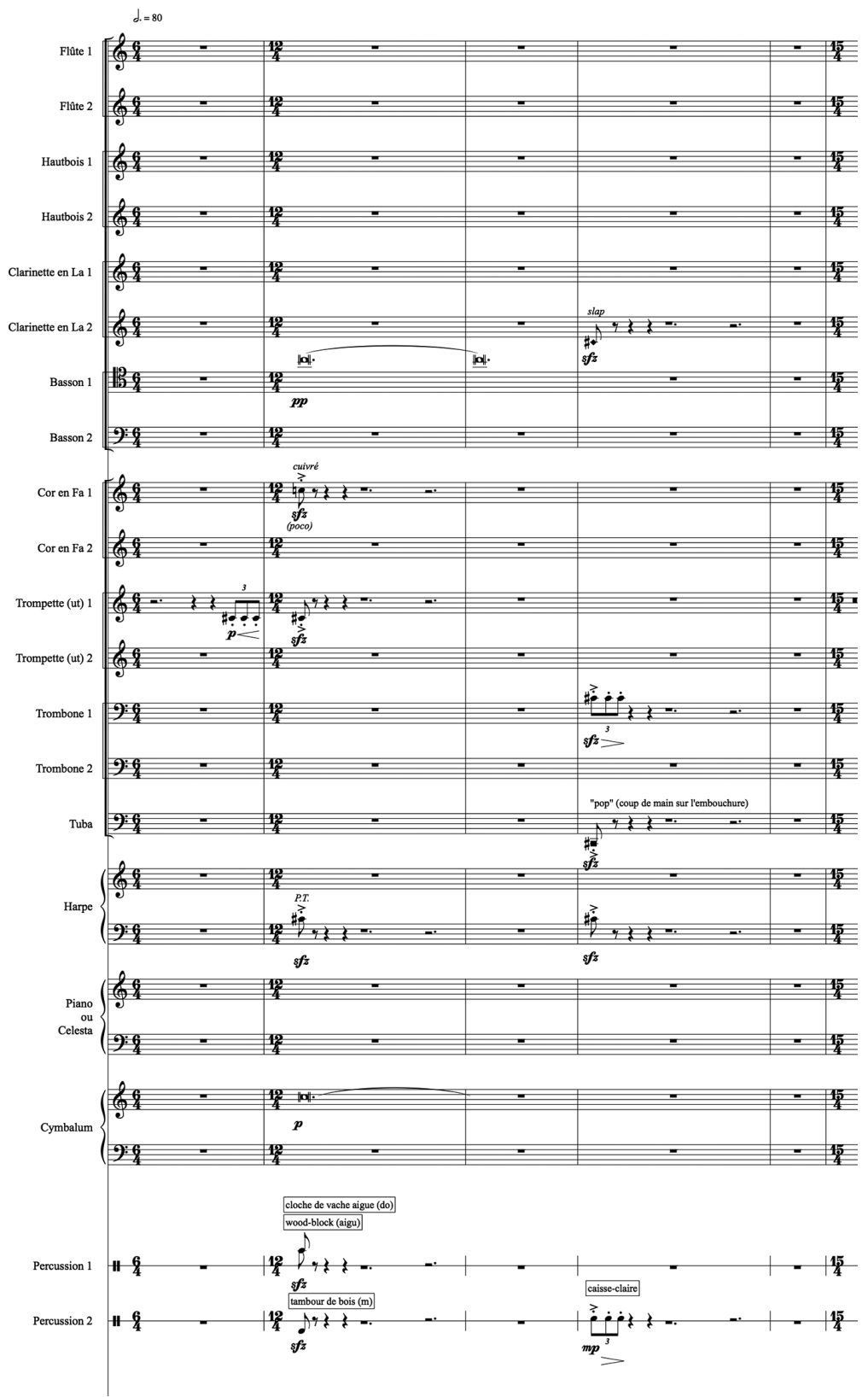

Ejemplo 1: O. Strasnoy, Incipit, cc. 1-5 (detalle) ${ }^{14}$. (c) Gérard Billaudot Éditeur. Se reproduce con autorización.

14 La aclaración "detalle" en los ejemplos musicales indica que en estos no se incluye la totalidad de los instrumentos activos en el fragmento correspondiente. 
Los primeros compases exhiben así uno de los principios compositivos de la pieza: la conjunción de materiales disímiles en una resultante nueva. El material inicial se destaca por medio de un silencio de un compás entero, que luego se reitera con variantes que ponen de relieve otros principios: la expansión y la recurrencia. En el despliegue formal de la pieza se van a incorporar otros comienzos, como los de Herzog Blaubarts Burg op. 11 de Béla Bartók (cuerdas, cc. 14 ss.) (ver Ejemplo 2), o los de las sinfonías no. 3, op. 55 ("Eroica"), y no. 5, op. 67, de Ludwig van Beethoven. Esos comienzos se presentan siempre por primera vez reducidos a su mínima expresión (en el caso de la cita de la Quinta de Beethoven, se trata apenas de un acorde, c. 150) (ver Ejemplo 3).

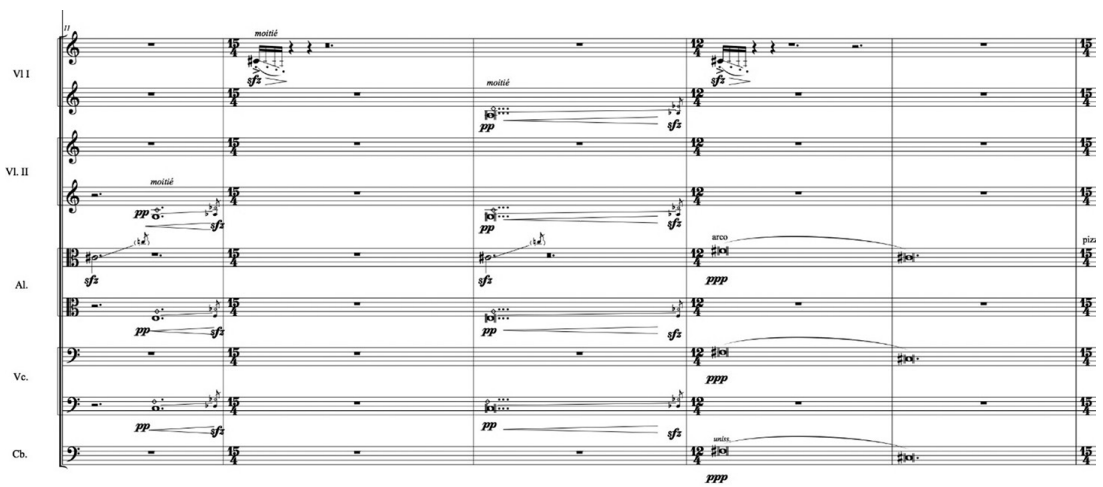

Ejemplo 2: O. Strasnoy, Incipit, cc. 11-15 (cuerdas, fragmento). (C) Gérard Billaudot Éditeur. Se reproduce con autorización.

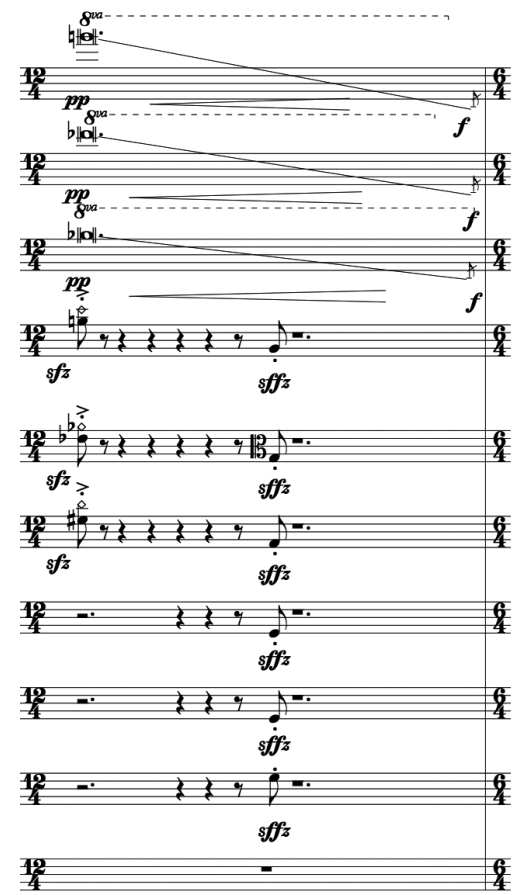

Ejemplo 3: O. Strasnoy, Incipit, c. 150 (cuerdas, fragmento). (C) Gérard Billaudot Éditeur. Se reproduce con autorización. 
No obstante, el apego al registro y la orquestación original, así como su heterogeneidad respecto del contexto en el que se emplazan, facilitan su reconocimiento en las apariciones subsiguientes. El procedimiento es análogo al que sigue Robert Schumann en "Florestán", de su Carnavalop. 9, en donde las citas se introducen una primera vez en forma velada, para exponerse más adelante plenamente reconocibles $^{15}$. Esos distintos materiales reaparecen a diferentes espaciamientos de tiempo, y la pieza concluye con los mismos fragmentos con los que había comenzado, transformados e invertido su sentido (hacen ahora de final). Los materiales se disponen en la simultaneidad sonora como un contrapunto compuesto no de líneas sino de fragmentos complejos y disímiles. La pregunta que subyace a Incipit es la de ¿cómo comenzar?, pero también, ¿‘cómo permanecer en el comienzo?, ¿cómo extenderlo sin que se desnaturalice? Incipit da forma musical a esa pregunta.

El título de $Y\left(10\right.$ '03") ${ }^{16}$, la segunda pieza del ciclo, remite no a la letra sino al significado del sonido que la representa en inglés. Allí está la clave que conduce a "Warum?", la tercera de las Phantasiestücke op. 12 para piano de Schumann, una pieza intimista que ofrece el subtexto para lo que constituye una suerte de movimiento lento de Sum. Como en Incipit, el comienzo del motivo de la pieza es citado literalmente. En "Warum?", la bordadura sobre la nota do suministra el impulso que conduce de re bemol a mi bemol (y de una subdominante inicial a la dominante); el motivo representa así el comienzo in media res de un proceso armónicamente direccionado. Strasnoy elide el mi bemol, extiende en cambio el re bemol, y de este modo transforma radicalmente el sentido del motivo: este se vuelve estático. El proceso al que da lugar no es armónico sino tímbrico: los violines, tocando $p p p$, en divisi y con sordina, junto con un trémolo de las campanas tubulares, reiteran y extienden ese motivo estático como una tenue resonancia vibrante, como una sombra (ver Ejemplo 4).

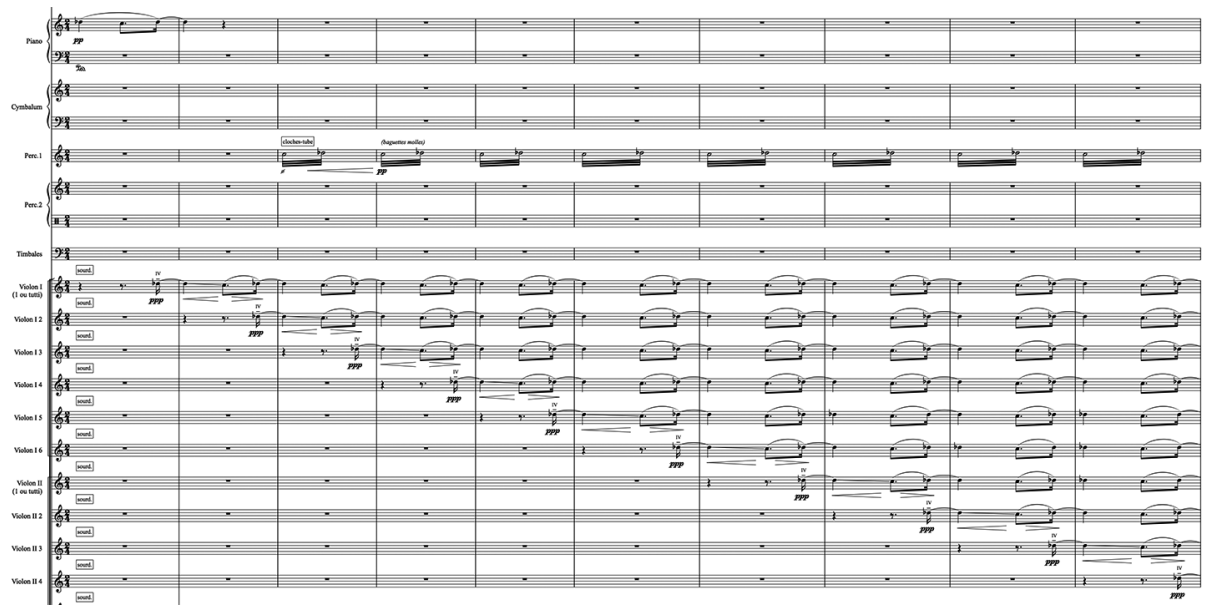

Ejemplo 4: O. Strasnoy, Y, cc. 1-10 (fragmento). (C) Gérard Billaudot Éditeur. Se reproduce con autorización.

Pocos compases más adelante se suman los cornos y las trompetas, que se alternan en la exposición del motivo. La orquesta no se presenta en $Y$ como una masa sonora, sino como un gran conjunto de cámara; la escritura es una filigrana.

Pero esa sombra tiene vida propia: el principio de fragmentación que se aplica al motivo se ve compensado por otro de derivación. Se escucha así una sonoridad indecidible entre la identidad

15 Cf. la interpretación de Charles Rosen de esta dinámica, entendida como representación de la memoria, en Rosen 1995: 98-101.

16 Sum no. 2 (2009-11), dedicada a Laura Baade. Obra encargada por la Radio France, y compuesta con apoyo de la Fundación J. S. Guggenheim. 
con el motivo de "Warum?" y su estallido en el medio orquestal. La figura por momentos se destaca, y en otros se subsume en la resonancia. Más adelante (letra E) aparece un elemento de ampliación: un arpegio que en "Warum?" tiene el estatuto de una apoyatura (c. 13) se constituye en $Y$ (a cargo del piano, que interviene siempre en momentos articuladores de la forma) en una figura autónoma, doblada y rítmicamente desdibujada, por parte de los clarinetes. El principio de fragmentación se radicaliza, la bordadura ya no retorna a la nota ornamentada, y todo lo que queda del gesto es el descenso cromático (cc. 60 ss.). De allí a los glissandi y trinos cromáticos de las cuerdas en cc. 82 ss. no hay más que un paso. Lo mismo se aplica al acompañamiento armónico del motivo. Strasnoy disocia estos aspectos y trabaja sobre los acordes como materiales autónomos, regidos eventualmente incluso, como en cc. 116 ss., por el descenso cromático. El sentido de la conclusión lo ofrece una restauración del motivo, siempre fragmentado aunque reconocible, a cargo de un violoncello, contrabajo y fagot (c. 186). El motivo asciende, como la entonación de una pregunta. La remisión a la historia no se limita en Sum a materiales particulares como el de Schumann, sino que se extiende a los tópicos con los que se representó musicalmente la analogía con el lenguaje.

Scherzo (7’51") ${ }^{17}$ se inspira más en el espíritu ligero de la forma que en su desarrollo histórico, que tiene no obstante su espacio en las citas del Scherzo de la Sonata para piano en si bemol mayor (D960) de Franz Schubert. Lo ligero descansa en la heterogénea procedencia y conformación de los materiales tanto como en el tratamiento que se les aplica. La heterogeneidad de los materiales es ostensible: un ritmo de chachachá, que se escucha en los metales, acompañados por glissandi ascendentes de las cuerdas; otro de tarantela, en cornos y trompeta (c. 15), el Scherzo de Schubert (piano en c. 12); materiales tomados de Underground (2004), música compuesta por el propio Strasnoy para la película muda homónima (1928) de Anthony Asquith (la percusión y el clavicémbalo) ${ }^{18}$. Estos materiales son objeto de una fragmentación tal, que suenan como si un obstáculo exterior impidiera su desenvolvimiento. Scherzo está atravesada por la idea de la interrupción. Esta se hace posible por el hecho de que los fragmentos aparecen como mutilados, inconclusos a pesar suyo. A esta sensación de una continua interrupción contribuyen los frecuentes cambios métricos, así como las alternancias entre los conjuntos instrumentales que Strasnoy dispone en la orquesta, y que están asociados de manera relativamente constante con los diferentes materiales.

Este efecto resulta de la técnica del montaje que emplea Strasnoy en esta pieza. Los materiales se ofrecen en un primer momento breves y reconocibles (figurativos, podría decirse, tanto por su condición representativa como por su carácter musicalmente perfilado) ${ }^{19}$, algunos de ellos reducidos incluso al papel de una puntuación. En el caso de los fragmentos del Scherzo de Schubert, estos aparecen y desaparecen tan velozmente que lo motívico termina por escucharse como color. Cuidadosamente dispuestos en la textura orquestal, la composición trata en un primer momento estos materiales como configuraciones cristalizadas, y se ocupa así de su enlace y del ritmo de sus alternancias y recurrencias.

Paulatinamente, en el curso del movimiento, los materiales se expanden (tanto en el tiempo como en la textura, en una progresiva ocupación cabal del dispositivo instrumental) y se vuelven alternativamente excluyentes (cc. 92 ss.; 100 ss.; 131 ss.; 175 ss.; 206 ss.; 260 ss. -entre ellos hay breves interrupciones, que producen invariablemente una modificación en la textura-). Sobrepuestos por unos momentos a la interrupción, se desarrollan y por eso mismo, de alguna forma, se descaracterizan. La interrupción emerge, en la última sección (cc. 260 ss.), en el plano del ritmo. La textura se entrecorta, el efecto es el de una continuidad iterada. A modo de compensación, esta sección no es interrumpida: la pieza concluye con una paulatina extinción. La regularidad rítmica y de frase característica del scherzo como forma es objeto en Scherzo de una deformación y de una transferencia. La periodicidad rítmica se vuelve interrupción imprevista; el contraste entre las frases, una proliferación de materiales heterogéneos.

Björn Haile observa, a propósito de Die Stücke der Windrose für Salonorchester (1988-94) de Mauricio Kagel, que “... la técnica compositiva no implica una simple presentación y yuxtaposición sino más bien una transformación e integración. El interés musical reside en la transformación y elaboración

17 Sum no. 3 (2005, rev. 2011), dedicada a Marc-Olivier Dupin. Obra encargada por la Orchestre National d'Ile de France.

18 Strasnoy, Underground (2004), música para la película de cine mudo Underground de Antony Asquith (1928), estrenada en el Museo del Louvre de París en 2004. Ed. Le Chant du Monde.

19 Cf. el concepto de figura del propio compositor en Strasnoy 2007: 295. 
de materiales por parte de Kagel, no en el material original como tal”20. De modo análogo, tampoco en Scherzo descansa el interés en la elección de los materiales por sí mismos, sino mucho más en sus relaciones con los otros, la disposición de que son objeto en el montaje y la dinámica que este asume en el desenvolvimiento de la forma ${ }^{21}$.

The End (9'44") ${ }^{22}$ establece una simetría complementaria con Incipit. La pregunta por la forma musical es ahora una pregunta por el final. La pieza comienza con una reproducción literal de los últimos 21 compases de la sinfonía no. 8, op. 93, de Beethoven (IV mov., cc. 482-502), una sucesión tan enfática como mecánica de acordes de dominante y tónica. A diferencia de Incipit, en donde las citas representan soluciones históricamente singulares al problema del comienzo, en esta pieza los compases de Beethoven cuentan más bien como una representación emblemática de la cadencia orquestal $^{23}$. The End trabaja sobre la convención; toma como punto de partida las fórmulas de clausura del género sinfónico. La pieza se configura como relectura irónica de uno de los momentos de la forma más permeados por las convenciones del estilo, y se extiende en el interior de ese momento conclusivo, prolongándolo y al mismo tiempo desnaturalizándolo. Estos materiales se reiteran, se desgreñan y finalmente diluyen (ver Ejemplo 5).

La ironía no solo está dada por la distancia histórica. La duración de esa cadencia repetida del Allegro vivace de Beethoven se explica por un sentido de la proporción formal con relación a la totalidad del movimiento y de la obra misma. Fragmentada de su contexto y ubicada en The End al comienzo del movimiento, pierde, por el mero efecto de la disposición, su direccionalidad y se vuelve mecánica, exagerada. La desnaturalización conduce al ridículo y abre camino a la comicidad. En la música de Strasnoy la convención no es tanto objeto de ruptura como de parodia ${ }^{24}$.

Los Trois caprices de Paganini conforman un concierto para violín a partir de los 24 Caprices op. 1 para violín solo de Niccolò Paganini ${ }^{25}$. El concierto se configura a partir de una metonimia complementaria: por una parte, se enmarca con el comienzo y el final de los caprichos, con el no. 6 a modo de movimiento lento. A la inversa, la orquesta, que preserva la música original en la parte del solista, recrea un acompañamiento inexistente en aquella ${ }^{26}$.

20 Heile 2002: 295. ... compositional technique does not entail a simple presentation and juxtaposition but rather a transformation and integration. Musical interest resides in Kagel's transformation and elaboration of materials not in the original material as such.

21 La concepción de Strasnoy del montaje como la "herramienta principal de la dramaturgia musical" se pone de manifiesto en la denominación de su concierto para piano y orquesta de cámara de 2017, Kuleshov, en alusión al conocido efecto cinematográfico. Cf. Strasnoy 2020.

22 Sum no. 4 (2006), encargo de la Orquesta Filarmónica de la Radio Francia, estrenada el 3 de marzo de 2007, bajo la dirección de Jean Deroyer.

23 Es interesante por eso destacar que, si bien estrictamente se trata en este caso de una cita textual, su naturaleza confirma de alguna manera la "delgada línea demarcatoria" que la separa, de acuerdo con Corrado (1992: 36), de la cita estilística.

24 Esta no es menos crítica: es difícil rehuir la crítica social formulada en The End hacia la circulación reificada del repertorio tradicional en la programación de la mayor parte de las orquestas sinfónicas en el mundo. Cf. el análisis de Dino Vallatico de la pieza en Vallatico 2009: 20-21. Para un relevamiento más diferenciado de los modos de la ironía y sus implicancias culturales en la música argentina, cf. Ogas 2019.

25 Compuesto en 2011 por encargo de Radio France. Estrenada el 14 de enero de 2012 por Latica Honda-Rosenberg y la Orquesta Filarmónica de Radio France, dirigida por Dima Slobodeniouk.

$26 \mathrm{El}$ procedimiento tiene un antecedente, en el ámbito de la historia local, en Tintineo. Glosa scarlattiana (1936) para saxos, cornos, trombón, percusión, piano, xilofón, violines y contrabajo, de Honorio Siccardi. "Esta pieza consiste en la reproducción textual de la Sonata en Sol Mayor de [Domenico] Scarlatti -No. 445 ...-, ejecutada por el piano, con intervenciones del resto del inusual conjunto instrumental [...] que subraya, duplica, colorea de manera discontinua determinadas configuraciones" (Corrado 2010: 204. Cf. Otero de Scolaro 1993: 10). 


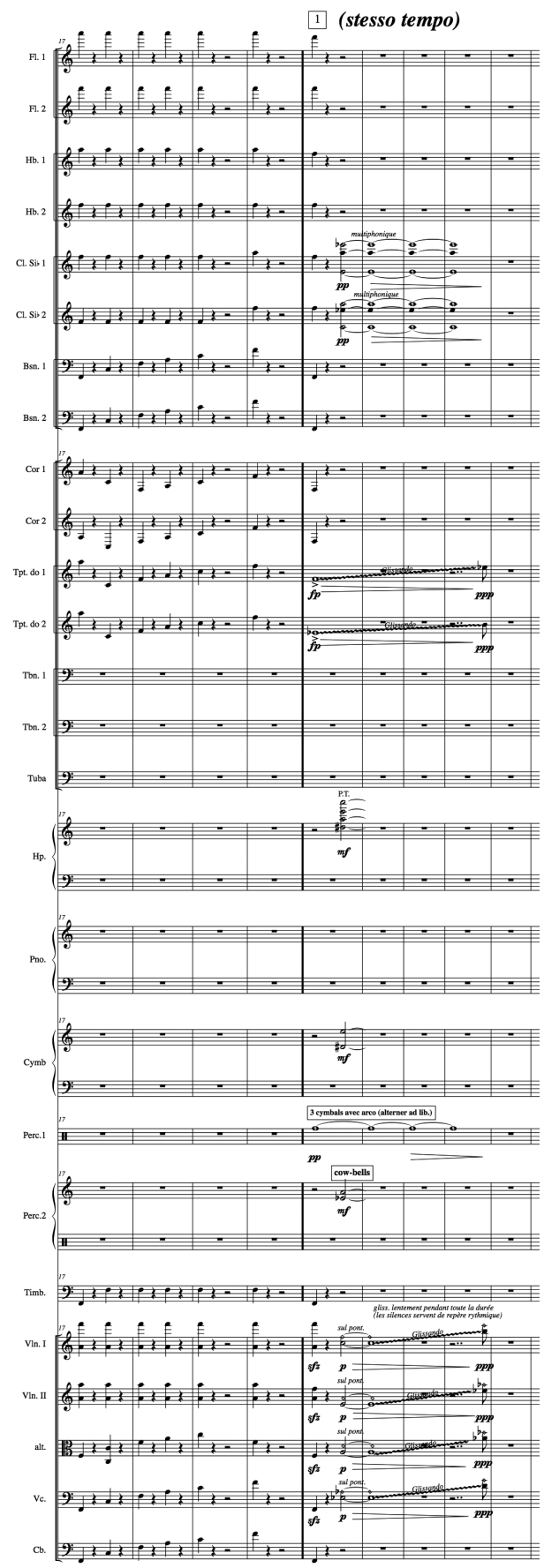

Ejemplo 5: O. Strasnoy, The End, cc. 17-25. Copyright @ 2006 Le Chant du Monde. Printed by Permission of Hal Leonard Europe Ltd. 
El capricho no. 1 (2'43”) despliega arpegios que se desplazan entre los extremos del registro en una figuración tan uniforme que los cambios rítmicos se vuelven verdaderos acontecimientos. La técnica de ricochet produce a su vez, para oídos contemporáneos, una interesante aspereza en la sonoridad. Strasnoy extiende estos elementos a nuevas dimensiones: los materiales se despliegan en el amplio espacio de la paleta orquestal. La figuración estalla en una multiplicidad de valores irregulares que desdibujan la subdivisión precisa del tiempo. Los cambios rítmicos del capricho producen acá cesuras en la parte del violín solista, así como modificaciones en el acompañamiento orquestal, que adquieren un papel formal.

La segunda pieza (4'47”) sigue fielmente el capricho No. 6. Sus trémolos veloces, que acompañan la melodía con un continuo tenue y estático, se extienden como un halo sobre la paleta instrumental, a la vez que se dispersan en una multiplicidad de ecos fragmentarios, en una delicada modulación de color.

El tercer movimiento (6'43") se basa en el no. 24; un tema con variaciones. La pieza mantiene esa disposición y el principio de variación se verticaliza: las diferentes secciones ofrecen un acompañamiento orquestal con materiales que, a diferentes ritmos, componen una especie de heterofonía abstracta: la oposición desdibujada entre la identidad y la diferencia se extiende desde los materiales musicales hasta sus tiempos históricos y procedencias culturales ${ }^{27}$.

Los Trois caprices reinventan la técnica medieval de la paráfrasis sobre una base nominalista: no rigen acá reglas generales, sino que son las particularidades de la música citada las fuentes de la derivación.

\section{III}

A diferencia de las interpretaciones que fijan el sentido de las músicas intertextuales en un gesto restaurador de las tradiciones negadas por las vanguardias (Williams 1997: 123-35), la música de Strasnoy se instala en la interrogación en torno a las condiciones históricas y actuales de la forma y los géneros. Esa interrogación tiene, en el caso particular de Strasnoy, un elemento de ironía que recuerda la de Mauricio Kagel ${ }^{28}$.

La rememoración de Kagel no es accidental. En la poética musical de ambos compositores ${ }^{29}$ puede identificarse un cosmopolitismo irónico, cuyo origen se relaciona con una tradición que Jorge Luis Borges (1974: 272) identificó con la cultura argentina moderna. Esta, modelada por la inmigración europea, tiene como una de sus marcas la negación de la distancia geográfica respecto de sus referentes culturales (Cf. Corrado 1997: 81; Sarlo 2003: 7-17). Pero esa distancia de alguna forma subsiste, y lo que resulta de esa relación particular entre la proximidad y la distancia posibilita una cierta irreverencia e ironía para la apropiación de los modelos culturales más disímiles. La posición irónica de poéticas como la de Strasnoy puede entenderse así como correlato musical de lo que Beatriz Sarlo denomina una "teoría borgeana de la literatura nacional", la que se basa en dos postulados:

27 Acerca de la heterofonía entendida como desdibujamiento de la oposición entre identidad y alteridad cf. Fessel 2010.

28 Hay algunos paralelos biográficos, además de estéticos, entre estos dos compositores. Nacidos en Argentina en familias de origen judío establecidas en Buenos Aires, terminaron radicándose en Europa y desarrollando ahí una exitosa carrera profesional. Kagel, que había tenido antes de partir para Alemania una actuación destacada en el marco de la Agrupación Nueva Música (cf. Richter-Ibáñez 2014), se mantuvo relativamente ausente de la escena musical argentina tras su partida, excepto por una visita aislada en 1974 y su regreso para un festival organizado en su homenaje en 2006 (cf. Marra de la Fuente 2008; Buch y Juárez 2019). Strasnoy, en cambio, partió hacia Francia muy joven, sin una inserción todavía significativa en la escena musical de Buenos Aires. Mantiene, sin embargo, desde 2002 una presencia sostenida como compositor, director, intérprete e incluso docente (en el Festival Nueva Ópera) en el campo musical local. Muchas de sus obras escénicas se han presentado en el Teatro Colón (Réquiem, en 2014, y El baile, en 2019, en la sala principal; Geschichte, en 2012, en su Centro de Experimentación), el Teatro General San Martín (Fábula en 2005; Cachafaz en 2012), la Usina del Arte (Preparativos de bodas, en 2016) y el Teatro Argentino de La Plata (Fábula en 2009).

29 Así como en la de Gerardo Gandini. Cf. Monjeau 2018: 202. 
que toda la literatura universal es la tradición de la literatura argentina [...]; y que los marginales (es decir: los argentinos, los americanos) tienen una libertad respecto de la tradición de la que no gozan los escritores de naciones culturalmente consolidadas, para quienes la transgresión es un acto de ruptura más violento y excluyente. El pasado literario, que restringe a los europeos, ofrece un campo de libertades irrestrictas para el escritor argentino (Sarlo 2003: 107).

Strasnoy, como Borges en el análisis de Sarlo, "se maneja con la soltura de un marginal que hace libre uso de todas las culturas" (Sarlo 2003: 14).

La apelación a la historia como reservorio de materiales disponibles (en tanto estéticamente legitimados para la contemporaneidad) no se adscribe entonces simplemente, en la poética de Strasnoy, a una de las orientaciones de la música reciente, sino que puede leerse también en ella un posicionamiento crítico respecto de una identidad homogénea, plenamente diferenciada de otras tradiciones y culturas. Esa crítica ilumina la paradoja de un cosmopolitismo que encarna una de las tradiciones idiosincrásicas de la música argentina (Cf. Gandini 1984; Corrado 1997).

Son significativos en ese sentido las similitudes que exhibe el modernismo tardío argentino (en compositores como Kagel, Gandini o Strasnoy) ${ }^{30}$ respecto de la producción de los compositores neoclásicos de la década del treinta, en la medida en que ambos hacen una análoga apelación a la historia. En la segunda, de acuerdo con Omar Corrado,

... se trata de tomar objetos, recortarlos de su contexto y procesarlos con herramientas "modernas", sofisticadas, especulativas, con lo que se confirma la idea neoclásica, y se refuerza la voluntad de objetividad, el distanciamiento puesto en práctica para la construcción de un lenguaje no mimético, autorreflexivo, que pone en escena la "objetualidad" y la técnica compositiva por sobre la ilusión realista, evocativa o sentimental ${ }^{31}$.

Las analogías no se limitan al plano de la configuración de los materiales musicales, sino que se extienden al de la recepción. Como observa Corrado, si la reevaluación del neoclasicismo europeo como una de las expresiones del modernismo estético es relativamente reciente, esa identificación fue sin embargo operativa en la misma época de su producción en el ámbito local ${ }^{32}$.

Estas analogías entre el neoclasicismo y el modernismo tardío ponen de relieve la continuidad, por medio de diferentes expresiones históricas, de un cosmopolitismo estético universalista en la cultura argentina $^{33}$. Esta continuidad es paralela a la que se plantea entre los nacionalismos de las primeras décadas del siglo XX y el latinoamericanismo surgido en los años setenta ${ }^{34}$, expresiones todos de una

30 Acerca de la distinción entre el alto modernismo y el modernismo tardío en la escena de la música europea, cf. Metzer 2009: 3.

31 Corrado 2010: 203. Es evidente que la retórica romántica de la música del siglo XIX no representa ya para el modernismo tardío, tal como se puede oír por ejemplo en " $Y$ ", un elemento con una fuerza tal como para requerir un distanciamiento pronunciado. Como observa Corrado (2010: 211), el antirromanticismo no era tan fuerte tampoco en el neoclasicismo argentino como en su equivalente europeo. No se dan en el primero, sin embargo, dos aspectos decisivos del segundo, y que sí se encuentran en el modernismo tardío: "la música sobre música, la reconstitución o reinterpretación de obras del pasado" (Corrado 2010: 203) y la parodia.

32 Corrado 2010: 178 y 218. De un modo similar, algunas de estas expresiones musicales, adscriptas en ocasiones al posmodernismo, pueden ser mejor interpretadas como una expansión del modernismo estético.

33 Hay elementos que apuntan a la posibilidad de pensar también en una concatenación histórica. Como señala Corrado, "la persistencia del neoclasicismo puede verificarse en la obra de músicos argentinos de las generaciones siguientes. Sus resonancias se perciben, por lo menos, hasta los tardíos 50, colocadas en contextos más heterogéneos o eclécticos, cruzadas con y superpuestas a configuraciones de lenguaje de otras proveniencias, ingresados posteriormente al campo compositivo local" (Corrado 2010: 223). El empleo de citas en la obra de Ginastera (Sottile 2016) puede haber representado así, por su parte, una de las referencias para la elaboración de la poética intertextual de Gandini hacia fines de los años 60 .

34 Cf. Etkin 1986. 
misma estética identitaria ${ }^{35}$. Se trata de continuidades que, con características particulares en cada momento histórico, y con una relativa autonomía respecto de la escena cultural en la que operan ${ }^{36}$, atraviesan y articulan la historia reciente de la música de concierto argentina.

\section{BIBLIOGRAFÍA}

Adorno, Theodor Wiesengrund

2003 Filosofía de la nueva música, Obra completa, 12. Rolf Tiedemann (editor), Alfredo Brotons Muñoz (traductor). Madrid: Akal.

2004 Teoría Estética, Obra completa, 7. Rolf Tiedemann (editor), Jorge Navarro Pérez (traductor). Madrid: Akal.

2008 "Sobre la tradición", Crítica de la cultura y sociedad I, Obra completa, 10/1. Rolf Tiedemann (editor), Jorge Navarro Pérez (traductor). Madrid: Akal, pp. 271-280.

BLEEK, TOBIAS

2010 Musikalische Intertextualität als Schaffensprinzip. Eine Studie zu György Kurtágs Streichquartett Officium breve $o p$. 28. Saarbrücken: Pfau.

BORGES, JORGE LUIS

1974 "El escritor argentino y la tradición", Discusión. Obras completas. Buenos Aires: Emecé, pp. 267-274.

Buch, Esteban y Camila Jú́rez

2019 "La Argentina, la noche... y el Festival Kagel de 2006”, Revista Musical Chilena, LXXIII/231 (enero-junio), pp. 137-146.

Burkholder, J. Peter

1995 All Made of Tunes: Charles Ives and the Uses of Musical Borrowing. New Haven: Yale University Press.

Corrado, OMAR

1992 "Posibilidades intertextuales del dispositivo musical", Migraciones de sentido. Tres enfoques sobre lo intertextual. Santa Fe: Universidad Nacional del Litoral, pp. 33-51.

1997 "The Construction of the Otherness in Twentieth-Century Argentinean Music", World New Music Magazine, 7, pp. 81-88.

2010 Música y modernidad en Buenos Aires. 1920-1940. Buenos Aires: Gourmet musical.

Dahlhaus, CARL

1987 "New Music and the problem of musical genre", Schoenberg and the New Music. Derryck Puffett y Alfred Clayton (traductores). Cambridge: Cambridge University Press, pp. 32-44.

2000 "Traditionszerfall im 19. und 20. Jahrhundert“, Gesammelte Schriften vol. 1, H. Danuser (ed.) . Laaber: Laaber, pp. 180-195.

DANuser, HermanN

1988 „Zur Kritik der musikalischen Postmoderne“, Neue Zeitschrift für Musik, CXLIX/12, pp. 4-9.

1990 "Musikalische Zitat- und Collageverfahren im Lichte der (Post)Moderne-Diskussion", Jahrbuch: Bayerische Akademie der Schönen Künste, 4, pp. 395-409.

35 Una estética tan cosmopolita, por su parte, como la primera. La contraposición es análoga a la que se da en el campo de la literatura argentina entre el universalismo que reivindica Borges y las tradiciones derivadas del criollismo, objeto de su intervención polémica.

36 Esto se aplica al conjunto de lo que Pablo Ortiz (2007) caracterizó como la "generación diaspórica" de la música contemporánea argentina, que incluye naturalmente a Strasnoy entre sus integrantes. 
2014 "Postmodernes Musikdenken - Lösung oder Flucht?”, Gesammelte Vorträge und Aufsätze. Vol. 2. Hans-Joachim Hinrichsen, Christian Schaper y Laure Spaltenstein (editores). Schliengen: Argus, pp. 409-419.

2017 Metamusik. Schliengen: Argus.

De la Motte-Haber, Helga

1990 "Musikalische Postmoderne: Rückschau als Neubewertung", Jahrbuch: Bayerische Akademie der Schönen Künste, 4, pp. 384-394.

EtKin, MARiano

1986 "Los espacios de la música contemporánea en América Latina”, Pauta. Cuadernos de teoría y crítica musical, V/20 (octubre-diciembre), pp. 60-68.

Fessel, PABlo

2010 "El unísono impreciso. Contribución a una historia de la heterofonía", Acta musicologica, LXXXII/1, pp. 149-171.

GANDINI, GERARDo

1984 "Estar", II Jornadas sobre Música en el Siglo XX. Córdoba: s/d, s/np.

1995 Seminario "Objetos encontrados", dictado en la Facultad de Artes y Ciencias Musicales de la Universidad Católica Argentina. Transcripción inédita (s/d). Fondo Gerardo Gandini de la Biblioteca Nacional (16 f).

Genette, GÉrard

1989 Palimpsestos. La literatura en segundo grado. Celia Fernández Prieto (traductora). Madrid: Taurus.

HEILE, BJÖRN

2002 "Collage vs. Compositional Control: The Interdependency of Modernist and Postmodernist Approaches in the Work of Mauricio Kagel”, Postmodern Music / Postmodern Thought. Judy Lochhead y Joseph Auner (editores). Nueva York: Routledge, pp. 287-299.

Hicks, MichaEL

1984 "The New Quotation: its Origins and Functions". Tesis D.M.A, University of Illinois at Urbana-Champaign.

Kolleritsch, OtTo (ED.)

1993 Wiederaneignung und Neubestimmung. Der Fall „Postmoderne“ in der Musik. Studien zur Wertungsforschung 26. Viena: Universal Edition.

KRAMER, JONATHAN D.

1997 "Música y postmodernismo", Pauta. Cuadernos de teoría y crítica musical, XVI/63 (julioseptiembre), pp. 5-18.

KristeVA, Julia

1967 "Bakhtine, le mot, le dialogue et le roman", Critique, XXIII/239 (abril), pp. 438-465.

LochHead, Judy y Joseph Auner (Eds.)

2002 Postmodern Music / Postmodern Thought. Nueva York: Routledge.

Marra de la Fuente, Luciano

2008 "Mauricio Kagel (1931-2008): Nah und fern... Cercano y lejano", Tiempo de música, 29 de octubre. Disponible en: www.tiempodemusica.com.ar/noticia/noticia.ver. php?idpost=411\&idpagina=46; [acceso: 28 de junio, 2019]

Metzer, David

2003 Quotation and Cultural Meaning in Twentieth-Century Music. Cambridge: Cambridge University Press.

2009 Musical Modernism at the Turn of the Twenty-First Century. Cambridge: Cambridge University Press. 
MONJEAU, FEDERICO

2009 "Anotaciones sobre la presencia europea en la música argentina contemporánea", Los caminos de la música. Europa y Argentina. Jujuy: Universidad Nacional de Jujuy, pp. 135-149.

2018 "Gerardo Gandini. Esculturas schumannianas", Un viaje en círculos. Sobre óperas, cuartetos y finales. Buenos Aires: Mardulce, pp. 197-219.

Ogas, Julio

2019 "Hipertextualidad, ironía y posvanguardia. En torno a la música de Gerardo Gandini y Marta Lambertini en la década de 1980", Cuadernos de música iberoamericana, 32 (enero-diciembre), pp. 159-185. https://dx.doi.org/10.5209/cmib.65533

Ortiz, Pablo

2007 "Una generación diaspórica", Nuevas poéticas en la música contemporánea argentina. Escritos de compositores. Pablo Fessel (editor). Buenos Aires: Biblioteca Nacional, pp. 95-98.

Otero de Scolaro, Ana María

1993 Catálogo general de obras de Honorio Siccardi. Mendoza: Editorial Oeste Argentino.

Richter-Ibáñez, Christina

2014 Mauricio Kagels Buenos Aires (1946-1957). Kulturpolitik, Künstlernetwerk, Kompositionen. Bielefeld: transcript-Verlag.

Rosen, CHaRles

1995 The Romantic Generation. Cambridge, Mass.: Harvard University Press.

Sarlo, Beatriz

2003 Borges, un escritor en las orillas. Buenos Aires: Seix Barral.

SCHNEBEL, DiETER

1998 "Re-Visionen", comentario en el folleto del CD Re-Visionen. Wergo 6616-2.

Sottile, Antonieta

2016 "La práctica de la cita en Alberto Ginastera", Revista del Instituto Superior de Música, 16, pp. 131-156. https://doi.org/10.14409/ism.v0i16.6087

STEPHAN, RUDOLPH

1969 "Das Neue der Neuen Musik", Das musikalisch Neue und die Neue Musik. Hans-Peter Reinecke (editor). Mainz: Schott, pp. 47-64.

STRASNOY, OSCAR

2007 "Dos palabras", Nuevas poéticas en la música contemporánea argentina. Escritos de compositores. Pablo Fessel (editor). Buenos Aires: Biblioteca Nacional, pp. 295-304.

2020 "À propos Kuleshov", comentario en el folleto del CD Alexandre Tharaud, Klavierkonzerte. Erato 0190295323073.

Tillman, JoAKim

2002 "Postmodernism and Art Music in the German Debate", Postmodern Music / Postmodern Thought. Judy Lochhead y Joseph Auner (editores). Nueva York: Routledge, pp. 75-91.

VAllatico, Dino

2009 «La stratification de la mémoire», Oscar Strasnoy. La stratification de la mémoire. París: Ensemble 2e2m, pp. 19-23.

Wellmer, Albrecht

1993 Sobre la dialéctica de modernidad y postmodernidad. La crítica de la razón después de Adorno. José Luis Arántegui (traductor). Madrid: Visor.

Williams, Alastair

1997 New Music and the Claims of Modernity. Aldershot: Ashgate.

2001 Constructing Musicology. Aldershot: Ashgate.

2013 Music in Germany since 1968. Cambridge: Cambridge University Press. 


\section{Partituras}

BARTÓK, BÉLA

1925 Herzog Blaubarts Burg op. 11. Nueva York: Universal Edition (13641).

BeETHOVEN, LUDWIG VAN

1997 Symphonie Nr. 8 in F, op. 93. Jonathan Del Mar (editor). Kassel: Bärenreiter.

2015 Symphonie Nr. 5 c moll op. 67. Jens Dufner (editor). Munich: G. Henle Verlag (HN 4022).

2016 Symphonie Nr. 3 in Es dur, op. 55. Bathia Churgin (editora). Munich: G. Henle Verlag (HN $9810)$.

MaHLer, Gustav

1964 Symphony No. 5. Erwin Ratz (editor). Leipzig: C. F. Peters.

PAganini, Niccolò

201324 Capricci für Violine solo op. 1. Ernst Herttric (editor). Munich: G. Henle Verlag (HN $9450)$.

SCHUbERT, Franz

1888 Sonate in B dur. (Franz Schuberts Werke, Serie X, No. 15) Leipzig: Breitkopf \& Härtel (F.S. 107).

\section{Schumann, Robert}

1879a Carnaval. Scènes mignonnes sur quatre notes, op. 9. (Robert Schumanns Werke, Clara Schumann, editora). Leipzig: Breitkopf \& Härtel.

1879b Phantasiestücke op. 12. (Robert Schumanns Werke, Clara Schumann, editora). Leipzig: Breitkopf \& Härtel.

STRASNOY, OScar

2004 Underground. París: Ed. Le Chant du Monde.

2005 Scherzo (Sum no. 3). París: Ed. Le Chant du Monde.

2006 The End (Sum no. 4). París: Ed. Le Chant du Monde.

2009-11a Incipit (Sum no. 1). París: Gérard Billaudot Éditeur.

2009-11b Y (Sum no. 2). París: Gérard Billaudot Éditeur.

2011 Trois caprices de Paganini. París: Gérard Billaudot Éditeur.

STRAVINSKY, IgOR

1970 The Rite of Spring (Le Sacre du Printemps). Pictures of Pagan Russia. Nueva York: International Music Company (3082).

\section{Fonogramas}

STRASNOY, OSCAR

2013 Orchestral Works. Orchestre Philarmonique de Radio France. París: Aeon. AECD 1331 